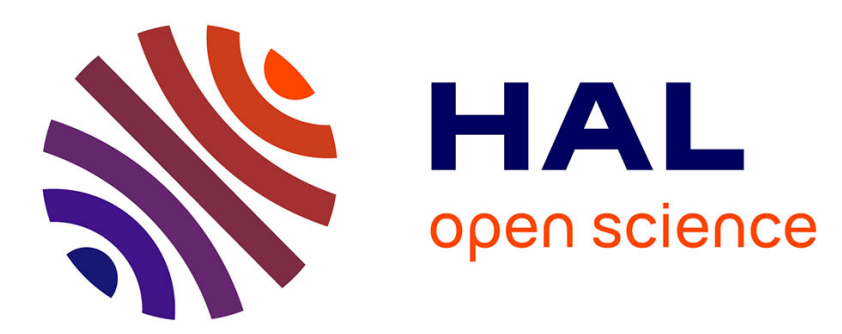

\title{
An escort for GPCRs: implications for regulation of receptor density at the cell surface.
}

Lamia Achour, Catherine Labbé-Jullié, Mark G.H. Scott, Stefano Marullo

\section{To cite this version:}

Lamia Achour, Catherine Labbé-Jullié, Mark G.H. Scott, Stefano Marullo. An escort for GPCRs: implications for regulation of receptor density at the cell surface.. Trends in Pharmacological Sciences, 2008, 29 (10), pp.528-35. 10.1016/j.tips.2008.07.009 . inserm-00311448

\section{HAL Id: inserm-00311448 https://www.hal.inserm.fr/inserm-00311448}

Submitted on 3 Sep 2008

HAL is a multi-disciplinary open access archive for the deposit and dissemination of scientific research documents, whether they are published or not. The documents may come from teaching and research institutions in France or abroad, or from public or private research centers.
L'archive ouverte pluridisciplinaire HAL, est destinée au dépôt et à la diffusion de documents scientifiques de niveau recherche, publiés ou non, émanant des établissements d'enseignement et de recherche français ou étrangers, des laboratoires publics ou privés. 
An escort for GPCRs: implications for regulation of receptor density at the cell surface.

Lamia Achour ${ }^{1,2}$, Catherine Labbé-Jullié ${ }^{1,2}$, Mark GH Scott ${ }^{1,2}$ and Stefano Marullo ${ }^{1,2}$

1. Institut Cochin, Université Paris Descartes, CNRS (UMR 8104), 75014 Paris, France

2. INSERM, U567, 75014 Paris, France.

G-protein-coupled receptors (GPCRs) are dynamically regulated by various mechanisms, which tune their response to external stimuli. Modulation of their plasma membrane density, via trafficking between sub-cellular compartments, constitutes an important process in this context. Substantial information has been accumulated on cellular pathways, which remove GPCRs from the cell surface for subsequent degradation or recycling. In comparison, much less is known about mechanisms controlling trafficking of neo-synthesised GPCRs from intracellular compartments to the cell surface. Although GPCR export to the plasma membrane is commonly considered to mostly implicate the default, unregulated secretory pathway, an increasing number of observations indicate that trafficking to the plasma membrane from the endoplasmic reticulum may be tightly regulated and involve specific protein partners. Moreover, a new paradigm is emerging in some cellular contexts, in which stocks of functional receptors retained within intracellular compartments may be rapidly mobilized to the plasma membrane to maintain sustained physiological responsiveness.

\section{Established models of GPCR maturation}

Introduction

Polytopic proteins (spanning membranes several times) are synthesized by ribosomes attached at the cytosolic face of the endoplasmic reticulum (ER) and enter cotranslationally in the ER lumen via a translocation complex (the translocon), to which they are targeted by hydrophobic signal sequences (Figure 1). Membrane insertion of transmembrane domains is driven by the translocon and orientation signals contained in the polypeptidic chain itself and it is assisted by molecular chaperones and folding factors ${ }^{1,2}$. Most polytopic proteins fold properly with the aid of the general chaperone system, which comprises classical and lectin chaperones, in addition to enzymes that catalyze disulfide bond formation or peptidyl-prolyl cis-trans isomerization ${ }^{3,4}$. Once polytopic proteins have 
achieved their native conformation, they leave the ER and are transported through the secretory pathway to their destination. This complex ER machinery constitutes the major quality-control system for proof-reading newly synthesized proteins: folding-defective polypeptides are exported across the ER membrane into the cytosol and destroyed by the ER-associated degradation pathway (ERAD) ${ }^{5}$.

Several studies have investigated the implication of the general chaperone system in GPCR folding. The Hsp70 family ER luminal protein BiP/GRP78 is the master regulator of the ER. Assisted by Hsp40 family co-factors, BiP facilitates translocation of nascent chains in the ER lumen, participates in protein folding and oligomerization and contributes to the retrotranslocation of misfolded proteins to ERAD ${ }^{4}$. Some GPCRs, such as thyrotropin-releasing hormone receptor (TRH receptor) and lutenizing hormone receptor ( $\mathrm{LSH}$ receptor), were reported to interact with $\mathrm{BiP}^{6,7}$. LSH receptor, was also found to interact in the $\mathrm{ER}$ with GRP94, a member of the Hsp90 family and Bip cofactor ${ }^{7}$. GRP94 likely interacts with more advanced folding intermediates than $\mathrm{BiP}$, since it binds some substrates that have been released from $\mathrm{BiP}^{4}$. $\mathrm{N}$-glycosylation of the aminoterminal region or of extracellular loops (which are luminal in the ER) is common among GPCRs. Cotranslational addition of a Glucose $_{3}$ Mannose $_{9} \mathrm{~N}$-acetylglucosamine 2 chain to asparagine residues by the oligosaccharyltransferase provides binding sites for carbohydrate-binding lectin chaperones such as calnexin and calreticulin. After the removal of the 2 terminal glucoses by a glucosidase, monoglucosylated nascent proteins interact with lectin chaperones, the interaction being terminated by the cleavage of the last glucose by glucosidase II. Once released, correctly folded glycoproteins can exit the ER. In contrast, incorrectly or incompletely folded glycoproteins are re-glucosylated by glucosyltransferase promoting a renewed association with calnexin and calreticulin. Cycles of glucosylation and deglucosylation continue until the glycoprotein has either reached its native conformation or is targeted for degradation ${ }^{3}$. As expected from the GPCR glycosylation profile, multiple reports illustrate the interaction between GPCRs and carbohydrate-binding chaperones ${ }^{6-12}$. Interestingly, ER-retained receptor mutants were found to display enhanced interaction with both carbohydrate-binding chaperones and/or $\mathrm{BiP}^{9,13}$. Finally, several reports documented the degradation of wild type or mutant GPCRs by ERAD ${ }^{12,14,15}$. The developing field of the proteomic analysis of GPCR-associated protein complexes $^{16}$ will likely confirm that interaction with the general chaperone system is a common feature for all receptors.

\section{Post ER trafficking}

Exit of proteins from the ER occurs at ER exit sites, where buds are formed and coated with the COPII coat under the control of the Sar1p GTPase. Proteins released from the ER quality control machinery accumulate in these buds ${ }^{17}$. A recent study provided 
experimental evidence that ER exit of GPCRs is indeed mediated through Sar1-dependent COPII-coated vesicles ${ }^{18}$. Signals in the cytoplasmically exposed C-terminal tails of transmembrane protein cargos (i.e. the transmembrane proteins that are being transported in the secretory pathway) are likely involved in direct binding with components of COPII ${ }^{19}$. These signals comprise di-acidic motifs (DXE or similar) and pairs of aromatic (FF, YY or FY) or bulky hydrophobic (LL or IL) amino acid residues ${ }^{17}$. Cargo receptors for soluble secretory proteins present in ER buds also possess these motifs in their carboxyterminal tail. Many GPCRs contain similar ER export motifs ${ }^{20}$, suggesting that they might interact directly with COPII complex proteins, although experimental evidence for this is lacking.

In mammalian cells, protein traffic moving from ER-exit sites to the Golgi complex passes through the ER-Golgi intermediate compartment (ERGIC). ERGIC is a site of anterograde and retrograde sorting under the control of COPI coat proteins, Rab and Arf GTPases $^{21}$. Vesicles exiting from this compartment are either directed to the Golgi or back to the ER, depending on the cargo, the ARF-GTPase isoform involved in coat recruitment, and on Rab effectors. ERGIC mainly harbors two Rabs that have opposing functions. Rab2 likely promotes the formation of vesicles returning to the $E R^{22}$, whereas Rab1 isoforms are involved in ER to ERGIC and ERGIC to cis-Golgi transport ${ }^{23}$. Indirect evidence for GPCR trafficking through the ERGIC has been provided by studies analyzing the effects of Rab1 and Rab2 proteins on receptor export. Forward trafficking of both the angiotensin $A T_{1}$ receptor and the ß2-adrenoceptor were impaired by siRNA-mediated knockout of Rab1b and overexpression of dominant-negative Rab $1 \mathrm{a}^{24}$. Surprising, trafficking of the $\alpha_{2 \mathrm{~B}}$-adrenoceptor was not affected, suggesting receptor-specific pathways. The surface expression of both ß2and $\alpha_{2 B^{-}}$adrenoceptors was perturbed by Rab2 mutants or siRNA-promoted inhibition of $\operatorname{Rab} 2^{25}$.

The Golgi complex is composed of stacks of flattened cisternae. Each layer of the stack, from cis-Golgi to the trans-Golgi network (TGN) contains glycosyltransferases. ER to Golgi carriers join the Golgi stack by fusing with cis cisternae ${ }^{26}$. The transport mechanisms of cargo and enzymes through the Golgi stack has not been completely elucidated and lead to conflicting models ${ }^{27}$. Once in the Golgi, cargo proteins may be sorted to the plasma membrane, the endosomal system or the ER. Retrograde transport to the ER is likely involved in re-targeting misfolded proteins to the ERAD ${ }^{28}$. Other defective proteins are targeted to lysosomal degradation after sorting to endosomes ${ }^{28}$. Studies of $\delta$-opioid (DOP) receptor glycosylation demonstrated that its O-glycosylation (on Ser or Thre residues) and final processing of $\mathrm{N}$-linked oligosaccharides occur in different compartments of the Golgi ${ }^{29}$. Perturbing the function of the Rab6 GTPAse, which regulates vesicular transport in the Golgi $^{30}$, inhibited the anterograde transport of Drosophila rhodopsin ${ }^{31}$ and of mammalian GPCRs ${ }^{25}$. There is no evidence for GPCR sorting from the Golgi to endosomes or ER and it 
remains unknown whether GPCR targeting to the cell surface from the Golgi is regulated. However, a recent report indicates that the $\mathrm{N}$-terminus of the $\alpha_{2 B}$-adrenoceptor may contain a signal to exit from the Golgi. Indeed, a receptor mutant, in which adjacent Tyr and Ser amino acid residues were substituted, was totally trapped in this organelle ${ }^{32}$.

\section{GPCR oligomerization might control receptor maturation and cell surface translocation}

Most GPCRs may exist as either homodimers or heterodimers. Dimerization seems to occur in the ER where it could have an important role in biosynthesis and quality control of newly synthesized receptors ${ }^{33}$. Heterodimerization can mask retention signals present in the sequence of some receptors, such as the $\mathrm{GABA}_{\mathrm{B}(1)}{ }^{34}$, which are constitutively trapped in the $E R$ in the absence of maturation partners. In contrast, the mechanism by which GPCR homodimerization might affect ER exit remains to be elucidated. A plausible hypothesis is that homodimerization might help receptor folding. Association of nascent polypeptides with chaperones prevents unproductive interactions with the environment that result in protein aggregation $^{35}$. Hydrophobic regions (such as membrane spanning domains of GPCRs) are particularly prone to non-specific aggregation. Thus, the ordered association of two nascent GPCR polypeptides via their transmembrane regions (often constituting the dimerization interface) could hide a significant proportion of the exposed hydrophobic surface and facilitate correct folding. The hypothesis that in a GPCR dimer receptor protomers may serve as folding chaperones one to each other, is consistent with the fact that functional GPCR heterodimers have been obtained in reconstituted cell models containing receptors, which do not "meet" in real life. In these artificial conditions, where two distinct GPCR polypeptides are forced to enter simultaneously in the ER, if they display sufficient structure-driven propensity to assemble, they may form heterodimers. Homodimerization might also contribute to quality control. Dimeric receptors are likely to be structurally symmetric. Random mutations affecting the overall structure of one protomer, may generate asymmetry within the dimer. Checking for symmetry could represent a simple method for ER quality-control mechanisms to recognize and retain nascent mutations, for disposal via the ERAD. Consistent with this model, mutant ER-retained GPCRs generally display dominant negative effect of over wild type forms in heterozygous individuals or in reconstituted cellular models ${ }^{33}$.

\section{Changing Paradigms}

GPCRs displaying regulated translocation to the plasma membrane from intracellular stores.

It is commonly believed that, in the absence of agonist-promoted endocytosis, GPCRs are mainly expressed at the cell surface, but this may not always be the case. The 
protease-activated receptor (PAR) family represents a well-known example. Thrombin receptors (PAR1 and PAR2) are irreversibly activated by cleavage, internalized and degraded in lysosomes. A large pool of intracellular receptor, mostly localized in the Golgi apparatus and protected from activation by thrombin, is translocated to the plasma membrane upon activation of cell surface receptors. Replenishment of plasma membrane thrombin receptors is correlated with recovery of thrombin responsiveness ${ }^{36}$.

Similarly, regulated pools of intracellular dopamine D1 receptors exist in tubular renal cells. In these cells, receptor recruitment from cytosolic stores to the plasma membrane is elicited by agonist activation of cell surface receptors ${ }^{37}$ or via atrial natriuretic peptidedependent heterologous activation ${ }^{38}$. An analogous phenomenon was also reported for $\alpha_{1 A^{-}}$ adrenoceptors in response to neuropeptide $Y$ stimulation $^{38}$, leading to the concept that receptor recruitment to the plasma membrane might be a mechanism for receptor sensitization. Selective up-regulation of D1 receptor was subsequently reported in neuronal dendritic spines upon NMDA receptor activation and increased intracellular calcium ${ }^{39}$. The recruitment of renal D1 receptor seems to occur via Golgi-derived vesicles and requires an intact microtubular network ${ }^{40}$.

Another model of regulated cell surface GPCR delivery, is represented by DOP receptor in neuronal cells ${ }^{41}$. Only a small fraction of DOP receptors is localized at the neuronal plasma membrane ${ }^{42}$, consistent with their low physiological involvement in acute pain response ${ }^{43}$. Sustained stimulation of $\mu$-opioid receptors can redistribute DOP receptors to neuronal plasma membranes in vivo and improve DOP-dependent antinociceptive effects $^{44,45}$. It was suggested that cell surface translocation of DOP receptor from intracellular compartments might account for the enhanced effect of DOP-targeting drugs during chronic pain $^{41}$. Several stimuli may elicit DOP receptor translocation, including the rise in intracellular calcium by either release from intracellular stores or direct opening of ion channels ${ }^{39}$.

Several other GPCRs inefficiently expressed at the plasma membrane, such as the odorant receptors ${ }^{46}$, the human $\mathrm{GnRH}$ receptor ${ }^{47}$, the $\alpha_{1 \mathrm{D}}$-adrenoceptor ${ }^{48}$ and the LSH receptor ${ }^{49}$, might represent other candidates for regulated translocation to the cell surface.

The increasing number of non-conventional chaperones and escorts assisting GPCR translocation to the plasma membrane (Table 1).

Some proteins may necessitate the specialized assistance of specific chaperones in the ER to fold properly. These so-called "private" chaperones assist nascent proteins in various ways. Outfitters ${ }^{50}$, are chaperones or enzymes that directly participate in the folding of their cognate proteins. A few private chaperones involved in GPGR folding have been reported. NinaA and RANBP2, two cyclophilin type II proteins displaying peptidyl-prolyl cis- 
trans isomerase activity, function as chaperones for Drosophila and vertebrate rhodopsin, respectively ${ }^{51,52}$. Rhodopsin also interacts with HSJ1b, a protein member of the DnaJ/Hsp40 chaperone family ${ }^{53}$. In neurons, HSJ1 proteins, which function at the cytosolic face of the ER, facilitate the transfer of "client" proteins onto Hsc70 chaperones and their subsequent ubiquitylation and sorting to the proteasome ${ }^{54}$. Thus, HSJ1 isoforms likely participate in ERAD and protect neurons against cytotoxic protein aggregation. Another group of GPCR private chaperones falls in the category of escort proteins ${ }^{50}$, which bind nascent proteins in the ER and escort them to the Golgi complex and the plasma membrane.

During the past ten years, a vast array of membrane-associated or cytoplasmic proteins has been identified, which constitutively interact with GPCRs within intracellular compartments and facilitate their cell surface expression. These proteins functionally behave like GPCR chaperones or escorts although they often display other biological roles. They were often identified by expression-cloning approaches or two-hybrid screens aimed to identify accessory factors helping the functional expression of "difficult to study" receptors.

The first example of non-conventional escort proteins for GPCRs is represented by receptor-activity-modifying-proteins (RAMPs ${ }^{55}$ ). RAMPs are type-I single-transmembrane domain proteins with a large $\mathrm{N}$-terminal extracellular domain and a short $\mathrm{C}$-terminus. They were initially described as obligatory interacting partners for the cell surface expression of a Class-B ${ }^{56}$ GPCR, the calcitonin-like receptor. RAMPs remain associated with the receptor at the cell surface. Interestingly, depending on the associated RAMP, the ligand binding properties of the calcitonin-like receptor vary, RAMP1 inducing affinity for the calcitonin generelated peptide (CGRP) whereas RAMP2 determines an adrenomedullin receptor phenotype ${ }^{57}$. Subsequent studies uncovered that RAMPs also aid in the constitutive plasma membrane translocation of a Class-C GPCR, the calcium-sensing receptor (CaS $)^{58}$. However, some observations suggest that being an escort protein for GPCRs is not the principal physiological function of RAMPs. First, RAMPs are almost ubiquitous, contrasting with the restricted tissue distribution of calcitonin-like ${ }^{57}$ and CaS receptor ${ }^{58}$. Second, the cell surface expression of other RAMP-interacting Class-B GPCRs (VPAC, parathyroid hormone, glucagon and glucagon-like peptide receptors), is not affected by their association with RAMPs $^{55}$.

For a long time, the study of odorant receptors has been hampered by the lack of functional cell surface expression in heterologous cells, raising the hypothesis that odorant tissue must contain specific auxiliary factors regulating their plasma membrane trafficking. Single transmembrane proteins named RTP1, RTP2 (Receptor Transporting Protein 1 and 2) and REEP1 (Receptor Expression Enhancing Protein 1) were finally found to permit functional cell surface targeting of odorant receptors in fibroblasts ${ }^{46}$, reminiscent of previous studies in C. elegans, in which odorant receptor localization to olfactory cilia required 
interaction with the ODR-4 transmembrane protein $^{59}$. Members of the RTP and REEP families display a much more diffuse distribution than the olfactory epithelium, suggesting that these proteins may regulate other GPCRs and/or exhibit additional functions. In particular, RTP and REEP mRNAs were detected in human circumvallate papillae and testis, which are the sites of bitter taste (TAS2) receptor expression. Experiments in heterologous cells confirmed the enhancement of TAS2 receptor cell surface targeting upon interaction with RTP3-4 and REEPs ${ }^{60}$.

The mammalian vomeronasal organ, a small sensory organ located near the base of the nasal septum and involved in the detection of pheromones, contains specific Class- $C$ GPCRs, which function as pheromone receptors. These vomeronasal receptors require the association with M10s proteins for proper traffic to the plasma membrane ${ }^{61}$. M10s belong to the superfamily of MHC class-I molecules, but are exclusively expressed in the vomeronasal organ. As classical MHC molecules, M10s contain an open peptide-binding cleft and associate with ß2-microglobulin. It was proposed that M10s, in addition to their escort role, might modulate the ligand specificity of vomeronasal receptors (similar to RAMPs) or participate in neuronal plasticity ${ }^{62}$.

As for odorant receptors, it has been very difficult to obtain functional expression of exogenous adrenocorticotropin $\mathrm{MC}_{2}$ receptor, except in cells of adrenocortical origin, suggesting that $\mathrm{MC}_{2}$ receptor expression may require an adrenal-specific accessory factor. In a genetic disease, the familial glucocorticoid deficiency (FGD), the adrenal cortex is resistant to adrenocorticotropin. By investigating patients with $\mathrm{FGD}$ and normal $\mathrm{MC}_{2}$ receptor, mutations were identified in a gene encoding a 19-kDa single-transmembrane domain protein, named $\mathrm{MC}_{2}$ receptor accessory protein (MRAP). MRAP was found to interact with $M C 2 R$ and to regulate its trafficking from the endoplasmic reticulum to the cell surface ${ }^{63,64}$. This example illustrates particularly well the physiopathological relevance of the interaction between a GPCR and a "private" escort protein.

Another similar example comes from studies in mice. Abnormal serotonin signaling has been implicated in the pathophysiology of depression. Cell surface density and function of the serotonin $5-\mathrm{HT}_{1 \mathrm{~B}}$ receptors are decreased in knockout mice for $\mathrm{p} 11^{65}$ (also known as calpactin I- or annexin II-light chain) a member of the S100 EF-hand calcium-dependent signaling modulators ${ }^{66}$. These mice exhibit a depression-like phenotype. The distribution of p11 mRNA in the brain resembles that of $5-\mathrm{HT}_{1 \mathrm{~B}}$ receptor mRNA, p11 specifically interacts with $5-\mathrm{HT}_{1 \mathrm{~B}}$ receptors (not with other serotonin or dopamine receptors), and colocalizes with the receptor at the cell surface of transfected cells ${ }^{65}$. Interestingly, p11 is increased in the brain of mice treated with antidepressants and reduced in depressed patients.

As for $\mathrm{p} 11$, other GPCR-interacting proteins may control plasma membrane receptor targeting without traveling to the cell surface. A well-known example is the ER-membrane- 
associated protein, DRiP78. Overexpression or down-modulation of this putative twotransmembrane domain protein leads to $E R$ retention of $D_{1}$ receptors, reduced ligand binding, and impaired kinetics of receptor glycosylation ${ }^{67}$. DRiP78 binds to a FXXXFXXXF motif found in the C-terminus of various GPCRs, supporting the hypothesis that DRiP78 may function as a chaperone for several receptors. Accordingly, a subsequent study indicated a role of DRiP78 in the maturation of the $\mathrm{AT}_{1}$ angiotensin II receptor ${ }^{68}$. Noteworthy, DRiP78 also specifically interacts with $\mathrm{G} \gamma$ subunits of heterotrimeric $\mathrm{G}$ proteins, protecting them from degradation until a stable partner (cognate $G \beta$ subunit) is provided. These results suggest a chaperone role of DRiP78 in the assembly of G $\beta \gamma$ subunits ${ }^{69}$.

A membrane-associated Golgi protein, ATBP50 (for $\mathrm{AT}_{2}$ receptor binding protein of $50 \mathrm{kDa}$ ) was reported to bind to the cytoplasmic carboxyterminal tail of the angiotensin $A T_{2}$ receptor and to control its cell surface expression, as demonstrated by receptor retention within intracellular compartments after inhibition of ATBP50 expression ${ }^{70}$. ATBP50 and two splice variants of the same gene share two myosin-like coiled-coil regions and form homo and hetero-dimers in vitro. These proteins display a much broader distribution than the $A T_{2}$ receptor, consistent with additional functions or with a more general role of escort protein for other GPCRs.

Another example of intracellular protein, interacting with the carboxyterminal tail of a GPCR (and also the first intracellular loop) and regulating its cell surface expression, is represented by RACK1 (from Receptor for Activated C-Kinase 1) ${ }^{71}$. RACK1 is an ER protein that constitutively binds the thromboxane A2 receptor (TPß). The cell surface expression of TPß was directly correlated with the concentration of RACK1: in cells with low RACK1 after specific siRNA treatment, TPß was retained in the ER. Interestingly, RACK1 displays selectivity for GPCRs since its expression level was able to affect the cell surface distribution of the chemokine receptor CXCR4 but not that of the 32 -adrenoceptor or prostanoid DP receptors.

Comparable specificity was documented for GEC1, a 117-residue protein, member of the microtubule associated protein (MAP) family ${ }^{72}$. GEC1 interacts in the Golgi and the ER with the $\mathrm{C}$-terminus of $\kappa$-opioid (KOP) receptors, but not with that of $\mu$ or $\delta$ subtypes. GEC1 expression enhanced the level of mature fully glycosylated forms of KOP receptors, and facilitated trafficking of KOP receptor to the cell surface. GEC1 levels appear to be tightly regulated, as indicated by a toxic effect of overexpression. Moreover, because of its broad tissue distribution, GEC1 might participate in cell trafficking of other membrane proteins ${ }^{72}$.

Finally a number of GPCR-interacting proteins, such as the dynein light-chain subunit TcTex, Homer proteins and Filamin A, were reported to connect rhodopsin ${ }^{73}$, glutamate receptors $^{74}$ and dopamine ${ }^{75}$ receptors, respectively, to the cytoskeleton, participating by this mean to their final subcellular localization. At least in the case of the visual receptor, this 
targeting function is also associated with an escort/chaperone-like role, as indicated by toxic effects of rhodopsin mutations, which inhibit the interaction with $\mathrm{TcTex}^{73}$.

Proteins that negatively regulate GPCR export via retention.

A simple explanation of GPCR retention within intracellular compartments in the absence of appropriate signals of forward export or in the case of a lack of "private" chaperones or escort proteins, might be the persistent interaction with proteins of the general quality-control machinery. Although this hypothesis remains plausible, some observations argue for the existence of specific retention mechanisms.

For example, the second extracellular loop of PAR2 was shown to interact with the Nterminal domain of the Golgi-resident type I transmembrane protein p24A. PAR2 is trapped in the Golgi because of this interaction. Upon activation of cell surface PAR2, the small $G$ protein ARF1 is recruited in its GDP-bound form, to Golgi membranes, where a specific exchange factor activates ARF1. This process results in the dissociation of PAR2 from p24A and receptor sorting to the plasma membrane ${ }^{76}$. During development, a GPCR-retaining protein was reported to control the surface receptor availability of Frizzled (FZD), a GPCR, which promotes caudalizing signals. This ER-resident protein, Shisa, is specifically expressed in head ectoderm, where it binds to and inhibits cell surface trafficking of FZD. Shisa-mediated receptor retention thus constitutes a mechanism to control head-tail polarity ${ }^{77}$. Although evidence for receptor-specific retention mechanisms is still limited for GPCRs, other recent examples exist for growth-factor receptors ${ }^{78}$, suggesting that this field may rapidly evolve in the near future.

\section{Concluding remarks and perspectives.}

The emerging picture of GPCR trafficking from biosynthetic compartments to the plasma membrane appears much more sophisticated than expected, particularly if the recent hypothesis of large signaling complexes containing GPCRs, G proteins and effectors being assembled during maturation ${ }^{79}$, is confirmed by future studies.

Several receptors are retained within intracellular compartments waiting for external signals that control their release from molecular tethers. In most cases, the pathways connecting signaling events with receptor export and the entity of the tethers have not been identified yet. Moreover, the subcellular location of retained receptors is not unique, implicating at least the ER and the Golgi complex.

Many GPCRs are constitutively associated with a long list of "private" chaperones or escort proteins, which are necessary for their proper targeting to the plasma membrane. How general this phenomenon may be, what the mechanisms involved in receptor retention and release are and the potential connection between this phenomenon and signal-regulated 
transport remain to be elucidated. Moreover, these private chaperones, which often display other cellular functions, might actually assist multiple GPCRs and possibly other integral membrane proteins in their trafficking to the cell surface.

Several conserved motifs have been identified in the sequence of many GPCRs, which may have some role in their forward trafficking. These motifs represent a molecular code determining the association with proteins that retain or assist GPCR in their journey through biosynthetic compartments. Deciphering the code is still a task that lies ahead.

Finally, the issue of GPCR maturation and trafficking to the cell surface is already an important issue in human health, as several receptor mutants leading to intracellular retention have been identified, which cause disease via impaired signaling ${ }^{80}$. Maturation and trafficking of these mutated receptors can be improved by membrane-permeant small molecules, which bind to retained receptors and induce export-competent conformational changes $^{81}$. Thus, improving our knowledge on the routing regulation of this important class of membrane receptors will probably elicit the development of new therapeutical approaches to control the targeting of GPCRs at the plasma membrane.

\section{Acknowledgements}

Thank you to Michel Bouvier and Ralf Jockers for the critical reading of the manuscript. This work was supported by the Sidaction grant $N^{\circ} 23005-09-00 / A O 17-2$ to SM. 


\section{References}

1. Higy, M., et al. (2004) Topogenesis of membrane proteins at the endoplasmic reticulum. Biochemistry 43, 12716-12722

2. Krebs, M.P., et al. (2004) Quality control of integral membrane proteins. Trends Biochem Sci 29, 648-655

3. Ellgaard, L., and Helenius, A. (2003) Quality control in the endoplasmic reticulum. Nat Rev Mol Cell Biol 4, 181-191

4. Hebert, D.N., and Molinari, M. (2007) In and out of the ER: protein folding, quality control, degradation, and related human diseases. Physiol Rev 87, 1377-1408

5. Tsai, B., et al. (2002) Retro-translocation of proteins from the endoplasmic reticulum into the cytosol. Nat Rev Mol Cell Biol 3, 246-255

6. Siffroi-Fernandez, S., et al. (2002) Association of the thyrotropin receptor with calnexin, calreticulin and BiP. Efects on the maturation of the receptor. Eur J Biochem 269, 4930-4937

7. Mizrachi, D., and Segaloff, D.L. (2004) Intracellularly located misfolded glycoprotein hormone receptors associate with different chaperone proteins than their cognate wildtype receptors. Mol Endocrinol 18, 1768-1777

8. Rozell, T.G., et al. (1998) Association of gonadotropin receptor precursors with the protein folding chaperone calnexin. Endocrinology 139, 1588-1593

9. Morello, J.P., et al. (2001) Association of calnexin with wild type and mutant AVPR2 that causes nephrogenic diabetes insipidus. Biochemistry 40, 6766-6775

10. Lanctot, P.M., et al. (2006) Role of N-glycan-dependent quality control in the cellsurface expression of the AT1 receptor. Biochem Biophys Res Commun 340, 395-402

11. Rosenbaum, E.E., et al. (2006) Calnexin is essential for rhodopsin maturation, Ca2+ regulation, and photoreceptor cell survival. Neuron 49, 229-241

12. Lu, M., et al. (2003) Endoplasmic reticulum retention, degradation, and aggregation of olfactory G-protein coupled receptors. Traffic 4, 416-433

13. Fan, J., et al. (2005) A point mutation in the human melanin concentrating hormone receptor 1 reveals an important domain for cellular trafficking. Mol Endocrinol 19, 25792590

14. Petaja-Repo, U.E., et al. (2001) Newly synthesized human delta opioid receptors retained in the endoplasmic reticulum are retrotranslocated to the cytosol, deglycosylated, ubiquitinated, and degraded by the proteasome. J Biol Chem 276, 4416-4423

15. Robben, J.H., et al. (2005) Characterization of vasopressin V2 receptor mutants in nephrogenic diabetes insipidus in a polarized cell model. Am J Physiol Renal Physiol 289, F265-272

16. Daulat, A.M., et al. (2007) Purification and identification of $G$ protein-coupled receptor protein complexes under native conditions. Mol Cell Proteomics 6, 835-844

17. Barlowe, C. (2003) Signals for COPII-dependent export from the ER: what's the ticket out? Trends Cell Biol 13, 295-300

18. Dong, C., et al. (2008) Endoplasmic reticulum export of adrenergic and angiotensin II receptors is differentially regulated by Sar1 GTPase. Cell Signal 20, 1035-1043

19. Aridor, M., et al. (1998) Cargo selection by the COPII budding machinery during export from the ER. J Cell Biol 141, 61-70

20. Dong, C., et al. (2007) Regulation of $G$ protein-coupled receptor export trafficking. Biochim Biophys Acta 1768, 853-870

21. Appenzeller-Herzog, C., and Hauri, H.P. (2006) The ER-Golgi intermediate compartment (ERGIC): in search of its identity and function. J Cell Sci 119, 2173-2183

22. Tisdale, E.J. (2003) Rab2 interacts directly with atypical protein kinase C (aPKC) iota/lambda and inhibits aPKCiota/lambda-dependent glyceraldehyde-3-phosphate dehydrogenase phosphorylation. J Biol Chem 278, 52524-52530 
23. Moyer, B.D., et al. (2001) Rab1 interaction with a GM130 effector complex regulates COPII vesicle cis--Golgi tethering. Traffic 2, 268-276

24. Wu, G., et al. (2003) Distinct pathways for the trafficking of angiotensin II and adrenergic receptors from the endoplasmic reticulum to the cell surface: Rab1independent transport of a $G$ protein-coupled receptor. J Biol Chem 278, 47062-47069

25. Dong, C., and Wu, G. (2007) Regulation of anterograde transport of adrenergic and angiotensin II receptors by Rab2 and Rab6 GTPases. Cell Signal 19, 2388-2399

26. Trucco, A., et al. (2004) Secretory traffic triggers the formation of tubular continuities across Golgi sub-compartments. Nat Cell Biol 6, 1071-1081

27. Pfeffer, S.R. (2007) Unsolved mysteries in membrane traffic. Annu Rev Biochem 76, 629-645

28. Arvan, P., et al. (2002) Secretory pathway quality control operating in Golgi, plasmalemmal, and endosomal systems. Traffic 3, 771-780

29. Petaja-Repo, U.E., et al. (2000) Export from the endoplasmic reticulum represents the limiting step in the maturation and cell surface expression of the human delta opioid receptor. J Biol Chem 275, 13727-13736

30. Jordens, I., et al. (2005) Rab proteins, connecting transport and vesicle fusion. Traffic 6, 1070-1077

31. Shetty, K.M., et al. (1998) Rab6 regulation of rhodopsin transport in Drosophila. J Biol Chem 273, 20425-20430

32. Dong, C., and Wu, G. (2006) Regulation of anterograde transport of alpha2-adrenergic receptors by the $\mathrm{N}$ termini at multiple intracellular compartments. J Biol Chem 281, 38543-38554

33. Bulenger, S., et al. (2005) Emerging role of homo- and heterodimerization in G-proteincoupled receptor biosynthesis and maturation. Trends Pharmacol Sci 26, 131-137

34. Margeta-Mitrovic, M., et al. (2000) A trafficking checkpoint controls GABA(B) receptor heterodimerization. Neuron 27, 97-106.

35. Gething, M.J., and Sambrook, J. (1992) Protein folding in the cell. Nature 355, 33-45

36. Hein, L., et al. (1994) Intracellular targeting and trafficking of thrombin receptors. A novel mechanism for resensitization of a $G$ protein-coupled receptor. J Biol Chem 269, 27719-27726

37. Brismar, H., et al. (1998) Dopamine-induced recruitment of dopamine D1 receptors to the plasma membrane. Proc Natl Acad Sci U S A 95, 5573-5578

38. Holtback, U., et al. (1999) Receptor recruitment: a mechanism for interactions between G protein-coupled receptors. Proc Natl Acad Sci U S A 96, 7271-7275

39. Scott, L., et al. (2002) Selective up-regulation of dopamine D1 receptors in dendritic spines by NMDA receptor activation. Proc Natl Acad Sci U S A 99, 1661-1664

40. Kruse, M.S., et al. (2003) Recruitment of renal dopamine 1 receptors requires an intact microtubulin network. Pflugers Arch 445, 534-539

41. Cahill, C.M., et al. (2007) Trafficking of delta-opioid receptors and other G-proteincoupled receptors: implications for pain and analgesia. Trends Pharmacol Sci 28, 2331

42. Cahill, C.M., et al. (2001) Immunohistochemical distribution of delta opioid receptors in the rat central nervous system: evidence for somatodendritic labeling and antigenspecific cellular compartmentalization. J Comp Neurol 440, 65-84

43. Kieffer, B.L. (1999) Opioids: first lessons from knockout mice. Trends Pharmacol Sci 20, $19-26$

44. Cahill, C.M., et al. (2001) Prolonged morphine treatment targets delta opioid receptors to neuronal plasma membranes and enhances delta-mediated antinociception. J Neurosci 21, 7598-7607

45. Morinville, A., et al. (2003) Regulation of delta-opioid receptor trafficking via mu-opioid receptor stimulation: evidence from mu-opioid receptor knock-out mice. J Neurosci 23, 4888-4898

46. Saito, H., et al. (2004) RTP family members induce functional expression of mammalian odorant receptors. Cell 119, 679-691 
47. Janovick, J.A., et al. (2006) Regulation of G protein-coupled receptor trafficking by inefficient plasma membrane expression: molecular basis of an evolved strategy. J Biol Chem 281, 8417-8425

48. Uberti, M.A., et al. (2005) Heterodimerization with beta2-adrenergic receptors promotes surface expression and functional activity of alpha1D-adrenergic receptors. J Pharmacol Exp Ther 313, 16-23

49. Pietila, E.M., et al. (2005) Inefficient maturation of the rat luteinizing hormone receptor. A putative way to regulate receptor numbers at the cell surface. J Biol Chem 280, 26622-26629

50. Herrmann, J.M., et al. (1999) Out of the ER--outfitters, escorts and guides. Trends Cell Biol 9, 5-7

51. Baker, E.K., et al. (1994) The cyclophilin homolog NinaA functions as a chaperone, forming a stable complex in vivo with its protein target rhodopsin. Embo $\mathrm{J} 13,4886-$ 4895

52. Ferreira, P.A., et al. (1996) Cyclophilin-related protein RanBP2 acts as chaperone for red/green opsin. Nature 383, 637-640

53. Chapple, J.P., and Cheetham, M.E. (2003) The chaperone environment at the cytoplasmic face of the endoplasmic reticulum can modulate rhodopsin processing and inclusion formation. J Biol Chem 278, 19087-19094

54. Westhoff, B., et al. (2005) HSJ1 is a neuronal shuttling factor for the sorting of chaperone clients to the proteasome. Curr Biol 15, 1058-1064

55. Parameswaran, N., and Spielman, W.S. (2006) RAMPs: the past, present and future. Trends Biochem Sci 31, 631-638

56. Horn, F., et al. (1998) GPCRDB: an information system for G protein-coupled receptors.

Nucleic Acids Res 26, 275-279

57. McLatchie, L.M., et al. (1998) RAMPs regulate the transport and ligand specificity of the calcitonin- receptor-like receptor. Nature 393, 333-339

58. Bouschet, T., et al. (2005) Receptor-activity-modifying proteins are required for forward trafficking of the calcium-sensing receptor to the plasma membrane. J Cell Sci 118, 4709-4720

59. Dwyer, N.D., et al. (1998) Odorant receptor localization to olfactory cilia is mediated by ODR-4, a novel membrane-associated protein. Cell 93, 455-466

60. Behrens, M., et al. (2006) Members of RTP and REEP gene families influence functional bitter taste receptor expression. J Biol Chem 281, 20650-20659

61. Loconto, J., et al. (2003) Functional expression of murine V2R pheromone receptors involves selective association with the $\mathrm{M} 10$ and $\mathrm{M} 1$ families of $\mathrm{MHC}$ class $\mathrm{lb}$ molecules. Cell 112, 607-618

62. Olson, R., et al. (2006) MHC homologs in the nervous system - they haven't lost their groove. Current Opinion in Neurobiology 16, 351-357

63. Metherell, L.A., et al. (2005) Mutations in MRAP, encoding a new interacting partner of the ACTH receptor, cause familial glucocorticoid deficiency type 2. Nat Genet 37, 166170

64. Cooray, S.N., et al. (2008) The melanocortin 2 receptor accessory protein exists as a homodimer and is essential for the function of the melanocortin 2 receptor in the mouse y1 cell line. Endocrinology 149, 1935-1941

65. Svenningsson, P., et al. (2006) Alterations in 5-HT1B receptor function by $\mathrm{p} 11$ in depression-like states. Science 311, 77-80

66. Donato, R. (1999) Functional roles of S100 proteins, calcium-binding proteins of the EF-hand type. Biochim Biophys Acta 1450, 191-231

67. Bermak, J.C., et al. (2001) Regulation of transport of the dopamine D1 receptor by a new membrane- associated ER protein. Nat Cell Biol 3, 492-498.

68. Leclerc, P.C., et al. (2002) A polyaromatic caveolin-binding-like motif in the cytoplasmic tail of the type 1 receptor for angiotensin II plays an important role in receptor trafficking and signaling. Endocrinology 143, 4702-4710 
69. Dupre, D.J., et al. (2007) Dopamine receptor-interacting protein 78 acts as a molecular chaperone for G-gamma subunits before assembly with G-beta. J Biol Chem 282, 13703-13715

70. Wruck, C.J., et al. (2005) Regulation of transport of the angiotensin AT2 receptor by a novel membrane-associated Golgi protein. Arterioscler Thromb Vasc Biol 25, 57-64

71. Parent, A., et al. (2008) RACK1 regulates the cell surface expression of the G proteincoupled receptor for thromboxane A(2). Traffic 9, 394-407

72. Chen, C., et al. (2006) GEC1 interacts with the kappa opioid receptor and enhances expression of the receptor. J Biol Chem 281, 7983-7993

73. Tai, A.W., et al. (1999) Rhodopsin's carboxy-terminal cytoplasmic tail acts as a membrane receptor for cytoplasmic dynein by binding to the dynein light chain Tctex- 1 . Cell 97, 877-887

74. Ango, F., et al. (2000) Dendritic and axonal targeting of type 5 metabotropic glutamate receptor is regulated by homer1 proteins and neuronal excitation. J Neurosci 20, 87108716

75. Lin, R., et al. (2001) Dopamine D2 and D3 receptors are linked to the actin cytoskeleton via interaction with filamin A. Proc Natl Acad Sci U S A 98, 5258-5263.

76. Luo, W., et al. (2007) p24A, a type I transmembrane protein, controls ARF1-dependent resensitization of protease-activated receptor-2 by influence on receptor trafficking. $J$ Biol Chem 282, 30246-30255

77. Yamamoto, A., et al. (2005) Shisa promotes head formation through the inhibition of receptor protein maturation for the caudalizing factors, Wnt and FGF. Cell 120, 223235

78. Couturier, C., et al. (2007) Silencing of OB-RGRP in mouse hypothalamic arcuate nucleus increases leptin receptor signaling and prevents diet-induced obesity. Proc Natl Acad Sci U S A 104, 19476-19481

79. Dupre, D.J., et al. (2006) Seven transmembrane receptor core signaling complexes are assembled prior to plasma membrane trafficking. J Biol Chem 281, 34561-34573

80. Conn, P.M., et al. (2007) G protein-coupled receptor trafficking in health and disease: lessons learned to prepare for therapeutic mutant rescue in vivo. Pharmacol Rev 59, 225-250

81. Bernier, V., et al. (2004) Pharmacological chaperone action on G-protein-coupled receptors. Curr Opin Pharmacol 4, 528-533 


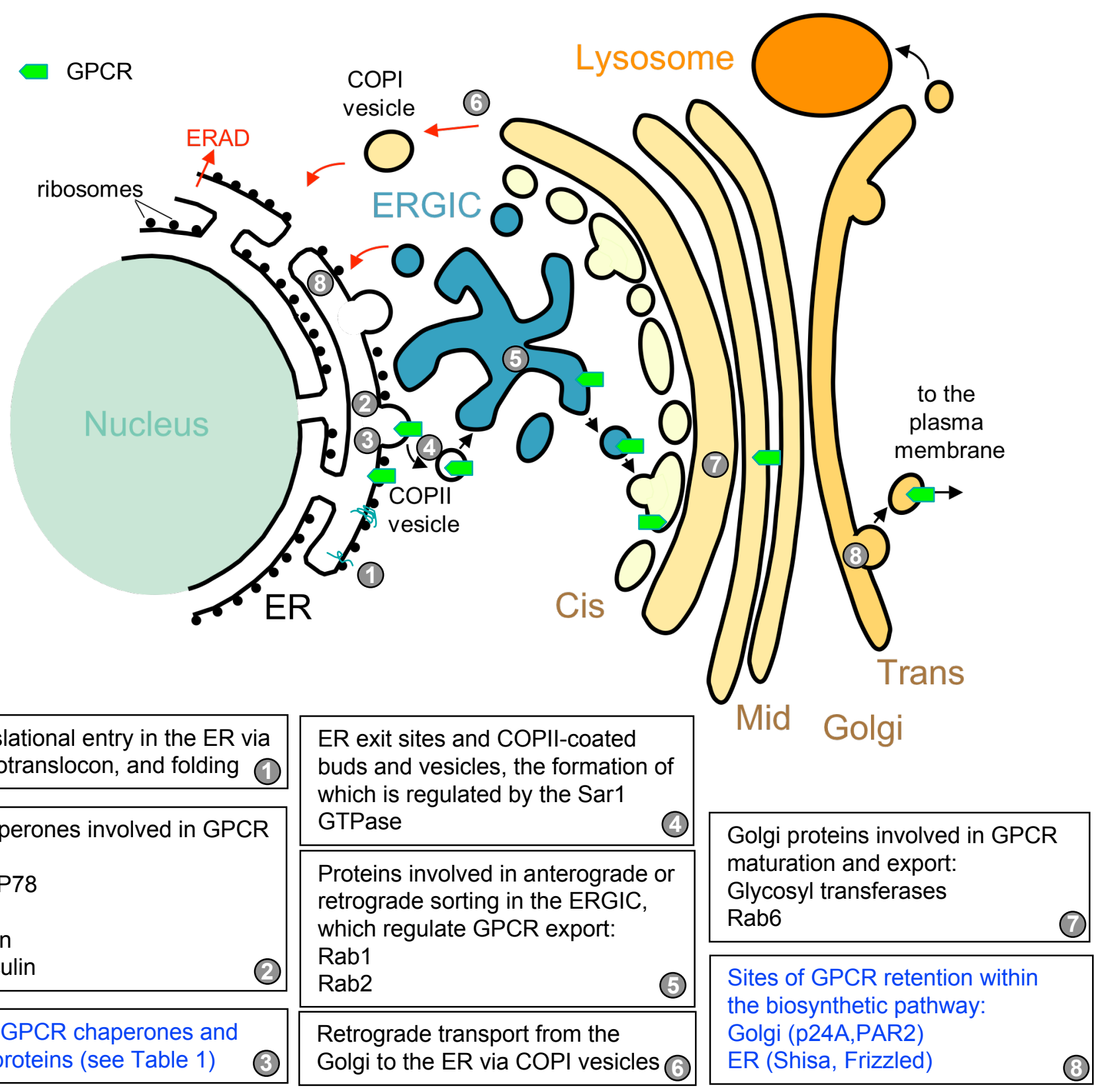

Cotranslational entry in the ER via the retrotranslocon, and folding

ER chaperones involved in GPCR folding:

Bip/GRP78

GRP74

Calnexin

Calreticulin

Private GPCR chaperones and escort proteins (see Table 1)
ER exit sites and COPII-coated and vesicles, the formation of which is regulated by the Sar1

Proteins involved in anterograde or retrograde sorting in the ERGIC, which regulate GPCR export: Rab1

Retrograde transport from the Golgi to the ER via COPI vesicles
Golgi proteins involved in GPCR maturation and export: Glycosyl transferases Rab6

Sites of GPCR retention within

ER (Shisa, Frizzled)

Figure 1. Subcellular events involved in GPCR maturation and cell surface export.

The scheme represents a step-by-step outline of GPCR synthesis and transport along the secretory pathway. Numbered boxes refer to either general mechanisms of protein transport (in black) or to GPCR-specific events (in blue). The proteins indicated in the boxes are described in the text and have all been shown to specifically contribute to GPCR transport.

ER: endoplasmic reticulum; ERGIC: ER-Golgi intermediate compartment; ERAD:ERassociated degradation pathway; COPII: coat protein II (or coatomer), involved in the transport of proteins from the rough endoplasmic reticulum to the Golgi apparatus. COPI: coat protein I, found on Golgi membrane at steady state, and involved in the formation of vesicles leaving the Golgi, including those of the retrograde transport to the ER. 
Table 1. Non-classical chaperones and escorts, which assist GPCR translocation to the plasma membrane.

\begin{tabular}{|c|c|c|c|c|c|}
\hline Name & $\begin{array}{l}\text { Type of } \\
\text { protein }\end{array}$ & $\begin{array}{l}\text { Other functions } \\
\text { Tissue distribution }\end{array}$ & $\begin{array}{l}\text { Chaperone } \\
(C) \\
\text { or Escort }(E)\end{array}$ & GPCR(s) & References \\
\hline RAMP (1-3 ) & Type 1, 1-TM & broad & $E$ & $\begin{array}{c}\text { AMY, CGRP } \\
\text { Cas }\end{array}$ & $\begin{array}{l}52-54 \\
55\end{array}$ \\
\hline RTP (1-4) & Type 1, 1-TM & broad & $E$ & $\begin{array}{l}\text { Odorant } \\
\text { Taste }\end{array}$ & $\begin{array}{l}43 \\
56\end{array}$ \\
\hline REEP & Type 1, 1-TM & broad & $E$ & $\begin{array}{l}\text { Odorant } \\
\text { Taste }\end{array}$ & $\begin{array}{l}43 \\
57\end{array}$ \\
\hline ODR4 & Tyре 1, 1-TM & olfactory neurons & $E$ & $\begin{array}{c}\text { C elegans } \\
\text { Odorant }\end{array}$ & 56 \\
\hline M10s & Type 1, 1-TM & $\begin{array}{c}\text { ß2- } \mu \text { globulin- } \\
\text { associated } \\
\text { MHC class I } \\
\text { vomeronasal organ }\end{array}$ & $E$ & Vomeronasal & 58,59 \\
\hline MRAP & Type 1, 1-TM & $\begin{array}{c}\text { adrenal } \\
\text { brain }\end{array}$ & E? & $\mathrm{MC}_{2}$ & 60,61 \\
\hline P11 & $\begin{array}{l}\text { Ca-binding } \\
\text { EF-hand } \\
\text { (helix-loop- } \\
\text { helix motif) } \\
\text { protein }\end{array}$ & $\begin{array}{c}\text { Ca-dependent } \\
\text { signaling modulator }\end{array}$ & C? & $5-\mathrm{HT} 1_{\mathrm{B}}$ & 62 \\
\hline DRiP78 & 2-TM & $\begin{array}{c}\text { broad } \\
\text { G } \beta \gamma \text { subunit } \\
\text { assembly }\end{array}$ & C? & $\begin{array}{l}\mathrm{D} 1 \\
\mathrm{AT}_{1}\end{array}$ & $\begin{array}{l}64 \\
65\end{array}$ \\
\hline ATBP50 & $\begin{array}{l}\text { myosin-like } \\
\text { coiled-coil } \\
\text { regions }\end{array}$ & broad & C? & $\mathrm{AT}_{2}$ & 67 \\
\hline RACK1 & $\begin{array}{l}7 \text { WD repeat } \\
\text { predicted } \\
\text { propeller } \\
\text { structure }\end{array}$ & $\begin{array}{c}\text { ubiquitous } \\
\text { receptor for } \\
\text { activated C-kinase } 1\end{array}$ & C? & $\begin{array}{c}\text { TPß } \\
\text { CXCR4 }\end{array}$ & $\begin{array}{l}68 \\
68\end{array}$ \\
\hline GEC1 & $\begin{array}{c}\text { microtubule } \\
\text { associated } \\
\text { Protein (MAP) }\end{array}$ & broad & C? & KOP & 69 \\
\hline
\end{tabular}

Abbreviations: AMY, amylin; CaS, calcium-sensing;CGRP, calcitotonin gene-related peptide; TM, transmembrane

"?" denotes a possible, but unconfirmed property 